Special issue of the 3rd International Conference on Computational and Experimental Science and Engineering (ICCESEN 2016)

\title{
Hardness Curves for 31CrMoV9 Steel after Gas Nitriding
}

\author{
N. SYla ${ }^{a}$, F. Aliaj ${ }^{a, *}$ AND M. RAMA ${ }^{b}$ \\ ${ }^{a}$ University of Prishtina, Department of Physics, Mother Theresa Str. 5, 10000 Prishtina, Kosovo \\ ${ }^{b}$ University of Mitrovica, Department of Materials and Metallurgy, 40000 Mitrovica, Kosovo
}

\begin{abstract}
This work is an experimental study of the hardness curve in the zone of diffusion for the gas nitriding process of $31 \mathrm{CrMoV} 9$ steel. 12 samples were subjected to gas nitriding at three different temperatures $-510^{\circ} \mathrm{C}, 550^{\circ} \mathrm{C}$, and $590^{\circ} \mathrm{C}$ - and for each temperature four different nitriding times were used. Hardness was measured with an automatic microhardness tester PCE from LECO with a load of HV0.1 $(0.9807 \mathrm{~N})$, and the distance between the points was $50 \mu \mathrm{m}$. It was found that the hardness of the diffusion layer changed from $602 \mathrm{HV}$ to $787 \mathrm{HV}$. The maximum surface hardness was found at $510^{\circ} \mathrm{C}$ after nitriding for $16 \mathrm{~h}$. Depending on the process parameters, the depth of the diffusion layer ranged from $270 \mu \mathrm{m}$ to $700 \mu \mathrm{m}$. From the results we can draw conclusions for the gradient curve of nitriding parameters, and from each curve we can find the depth of the diffusion of nitrogen in steel.
\end{abstract}

DOI: 10.12693/APhysPolA.132.484

PACS/topics: gas nitriding, hardness curve, nitriding potential, 31CrMoV9 steel

\section{Introduction}

Gas nitriding is a thermochemical process of surface hardening on ferrous materials $[1,2]$. This process is used to improve some surface properties such as wear, fatigue, corrosion, friction, and hardness [1-4]. This case involves atomic nitrogen from dissociating ammonia gas diffusing into the steel surface in the temperature range $500^{\circ} \mathrm{C}-$ $590^{\circ} \mathrm{C}[5,6]$. The nitriding of the steel can be visualized as bringing $\mathrm{N}_{2}$ gas into contact with the surface of the workpiece under extremely high pressure, which becomes possible by using $\mathrm{NH}_{3}$ mixed with $\mathrm{N}_{2}$ or $\mathrm{H}_{2}$ gas. This means that the fundamental reaction for this process is the catalytic decomposition of ammonia to form nascent (elemental) nitrogen [5].

The control parameters include time, temperature, and gas dissociation rate. In fact, the rate of dissociation expressed through nitriding potential is defined as $a_{n}=$ $p_{\mathrm{NH}_{3}} / p_{\mathrm{H}_{2}}^{1.5}$, where $p_{\mathrm{NH}_{3}}$ and $p_{\mathrm{H}_{2}}$ are the partial pressures of the ammonia and hydrogen gases, respectively $[5,6]$.

During the gas nitriding process, the reaction occurs not only at the surface but also inside the material because of nitrogen atoms' diffusion from the surface towards the matrix. Nitrogen diffused into a steel surface is combined with alloying elements to form a fine dispersion of alloy nitrides [3]. As a result of the diffusion of nitrogen into the steel, a very hard, wear-resistant and corrosion-resistant surface develops over a tough matrix. The depth to which nitrogen has penetrated is called the nitriding layer or nitriding zone, which consists of the compound layer and diffusion zone [5]. The compound layer, also known as the "white layer", because it is not attacked by alcoholic nitric acid etching, consists predominantly of $\varepsilon-\mathrm{Fe}_{2-3}(\mathrm{C}, \mathrm{N})$ and/or $\gamma-\mathrm{Fe}_{4} \mathrm{~N}$ phases and can

*corresponding author; e-mail: fisnik.aliaj@uni-pr.edu greatly improve resistance to wear and corrosion. Under the compound layer is the diffusion layer, which is composed of an interstitial solid solution of nitrogen dissolved in the ferrite lattice, and nitride and/or carbonitride precipitation for the alloy steels containing the nitrides forming elements, and is responsible for a considerable enhancement of hardness and fatigue endurance $[2,5]$.

\section{Experimental details}

The chemical analysis of steel $31 \mathrm{CrMoV} 9$ measured with spark emission spectrometer model JY-132F, is given in Table I.

TABLE I

Chemical composition of $31 \mathrm{CrMoV} 9$ steel [wt\%]

\begin{tabular}{c|c|c|c|c|c|c|c|c|c}
\hline \hline $\mathrm{C}$ & $\mathrm{Cr}$ & $\mathrm{Mn}$ & $\mathrm{V}$ & $\mathrm{Mo}$ & $\mathrm{Si}$ & $\mathrm{S}$ & $\mathrm{P}$ & $\mathrm{Al}$ & $\mathrm{Fe}$ \\
\hline 0.29 & 2.17 & 0.70 & 0.15 & 0.27 & 0.26 & 0.004 & 0.016 & 0022 & bal.
\end{tabular}

For our investigation we took 12 samples of dimensions $\varphi 35 \times 10 \mathrm{~mm}^{3}$, then labeled them and processed their surface by mechanically grinding them with successive grades of $\mathrm{SiC}$ paper, starting with 320-grit and proceeding to 400-, and 600-grit papers, using water to keep the specimens cool [2]. Prior to gas nitriding, the steel specimens were normalized in an $\mathrm{N}_{2}$ atmosphere at $860^{\circ} \mathrm{C}$ for $2 \mathrm{~h}$, followed by rapid cooling in oil, and then tempering at $630^{\circ} \mathrm{C}$ for $2 \mathrm{~h} \mathrm{[2].} \mathrm{After} \mathrm{thermal} \mathrm{treatment,}$ the specimens were ultrasonically cleaned in acetone for 5 min, dried in hot air, and then transferred to the nitriding environment. The gas nitriding was performed in air-doped ammonia atmosphere at $T=510^{\circ} \mathrm{C}, 550^{\circ} \mathrm{C}$, and $590^{\circ} \mathrm{C}$ for various nitriding times $\tau$. The nitriding parameters and the respective labels of the specimens are given in Table II. After gas nitriding, the specimens were cut in cross-section, mounted in resin, and subsequently ground and polished with a final polishing step of $1 \mu \mathrm{m}$. In order to avoid damaging and rounding off 
at the edges upon cross-sectional preparation, the specimens were protected by Ni-plating prior to mounting in resin.

The hardness was measured in the polished surfaces $[7,8]$ of samples with an automatic microhardness tester PCE from LECO. For this we used a small load of HV0.1 $(0.9807 \mathrm{~N})$, in which the distance between the two measuring points was $50 \mu \mathrm{m}$, while the load time was $10 \mathrm{~s}$ [9-11]. The total number of points in the sample was between 15 and 30 (depending on the nitriding parameters, i.e. on the depth of the nitrogen diffusion). We also measured the hardness at 5 points in the matrix zone at a depth of $3 \mathrm{~mm}$. Through these points, we found the hardness curves for all samples, then for each curve we calculated the following parameters:

- surface hardness $(S H)$,

- matrix hardness $(M H)$ i.e. hardness of the nonnitrided zone,

- increase in hardness $(\Delta H=S H-M H)$,

- depth of nitriding $\left(D_{n t}\right)$.

TABLE II

Gas nitriding parameters: temperature $\left[{ }^{\circ} \mathrm{C}\right]$, nitriding potential (NP) $\left[\mathrm{atm}^{-1}\right]$ and time $[\mathrm{h}]$, specimen labels SL, surface hardness $S H$, matrix hardness $M H$, increase in hardness $\Delta H$, and depth of nitriding $D_{n t}$.

\begin{tabular}{c|c|c|c|c|c|c|c}
\hline \hline$T$ & NP & $\tau$ & SL & $S H$ & $M H$ & $\Delta H$ & $D_{n t}$ \\
\hline \multirow{5}{*}{510} & \multirow{5}{*}{3.4} & 16 & $31-1$ & 787 & 298 & 482 & 305 \\
& & 64 & $31-3$ & 778 & 290 & 488 & 400 \\
& & 100 & $31-5$ & 776 & 287 & 489 & 500 \\
& & 9 & $31-9$ & 773 & 285 & 503 & 620 \\
550 & \multirow{3}{*}{3.0} & 16 & $31-11$ & 758 & 285 & 498 & 270 \\
& & 36 & $31-13$ & 727 & 303 & 424 & 520 \\
& & 64 & $31-15$ & 709 & 302 & 407 & 650 \\
& & 4 & $31-17$ & 744 & 290 & 454 & 280 \\
590 & \multirow{5}{*}{2.82} & 9 & $31-19$ & 630 & 283 & 347 & 380 \\
& & 16 & $31-21$ & 640 & 262 & 378 & 525 \\
& & 36 & $31-23$ & 602 & 278 & 324 & 700
\end{tabular}

\section{Results and discussions}

Hardness curves were plotted for all samples, as a result of the measurement of the hardness as a function of the depth (Fig. 1). In order to interpret the results more precisely, the hardness values were calculated in the surface and matrixes, as well as the increase in hardness and depth of nitriding $\left(D_{n t}\right)$, see Table II. Determination of the nitriding hardness depth was defined in accordance with the DIN 50190-3 standard. This is ascertained from the hardness curve and lies at a hardness limit of $50 \mathrm{HV}$ below the core hardness.

High values of hardness in the periphery are caused mainly by the iron nitrides in the compound layer, as well as by the formation of individual nitrides in the precipitation layer. It is known that chromium has a high affinity for forming bonds with nitrogen so precipitating as fine semi-coherent $\mathrm{CrN}$ nitrides with $B 1$-type structure, directly responsible for observed hardening [8].

The curves of hardness differ from each other in absolute value and in depth. Figure 2 shows the influence of temperature in hardness curves for nitriding time of $36 \mathrm{~h}$.

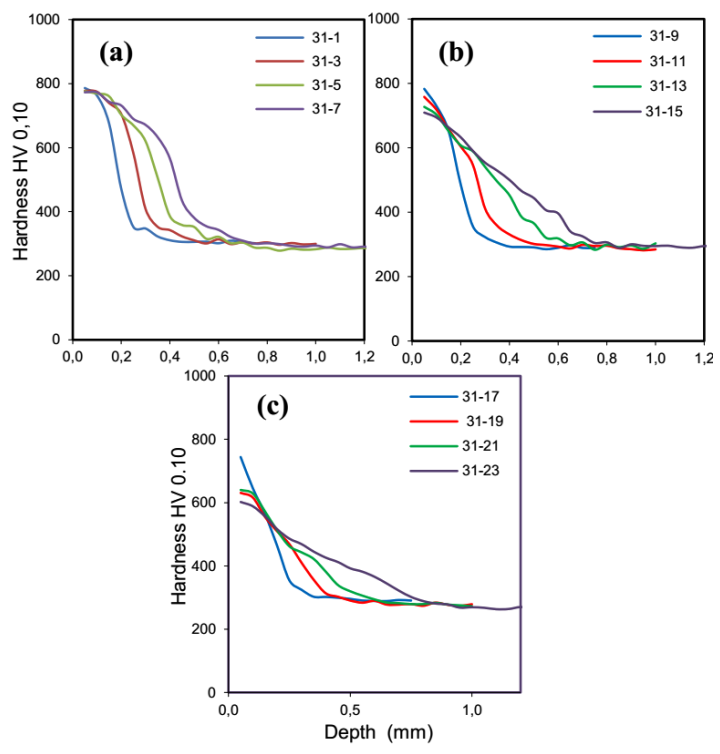

Fig. 1. The hardness curves at three temperatures: (a) $510^{\circ} \mathrm{C}$, (b) $550{ }^{\circ} \mathrm{C}$, and (c) $590{ }^{\circ} \mathrm{C}$.

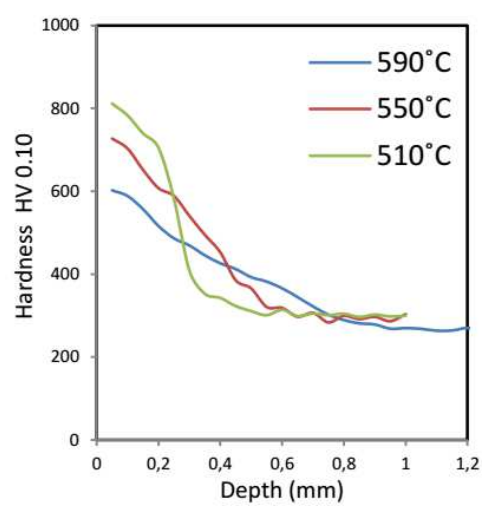

Fig. 2. Effect of nitriding temperature on the hardness curves for the duration of $36 \mathrm{~h}$.

\section{Conclusion}

- From Table II and Figs. 1 and 2, it can be seen that the depth of nitriding increased with increasing duration and temperature of nitriding. This can be explained because increased time provides more atomic nitrogen diffusion towards the matrix while an increased temperature raises the diffusion coefficient of nitrogen, providing the same effect [6]; 
- From Figs. 1 and 2 it can be seen that increasing duration and temperature decreases maximal hardness of the surface [12]. The reason for this is that discontinuous precipitation can occur by increase of the duration and the temperature, which may cause a reduction in hardness at the surface;

- As a result of the above-mentioned two effects, we can also derive a conclusion for the reduction in the gradient's curves with increasing duration and temperature.

\section{References}

[1] G.C. Efe, Mater. Technol. 48, 827 (2014).

[2] N. Syla, F. Aliaj, B. Dalipi, Acta Phys. Pol. A 130 83 (2016).

[3] S.Y. Sirin, K. Sirin, E. Kaluc, Mater. Character. 59, 351 (2008).

[4] N. Syla, F. Aliaj, Sci. Res. Essays 10, 615 (2015).
[5] E.J. Mittemeijer, in: ASM Handbook: Fundamentals of Nitriding and Nitrocarburizing, Eds. J. Dossett, G.E. Totten, Vol. 4A, ASM International, 2013.

[6] H. Selg, Ph.D. Thesis, University of Stuttgart, Germany 2012.

[7] O. Sahin, S. Uzunoglu, E. Sahin, Acta Phys. Pol. A 128, B-149 (2015).

[8] E. Karip, S. Aydin, M. Muratoğlu, Acta Phys. Pol. A 128, B-160 (2015).

[9] M. Boztas, S. Ozarslan, O. Sahin, Acta Phys. Pol. A 130, 357 (2016).

[10] H. Altan, F. Bilgic, Z. Arslanoglu, E. Kale, A. Köroğlu Kale, A. Altan, O. Sahin, Acta Phys. Pol. A 130, 394 (2016).

[11] Z. Arslanoglu, H. Altan, O. Sahin, M.G. Tekin, M. Adigüzel, Acta Phys. Pol. A 128, B-310 (2015).

[12] C. Ginter, L. Torchane, J. Dulcy, M. Gantois, A. Malchère, C. Esnouf, T. Turpin, Metallurgia Italiana 7-8, 29 (2006). 